\title{
Effect of different fusion types on kinematics of midfoot lateral column: a comparative biomechanical study
}

\author{
Genbin $\mathrm{Wu}^{1,2}$, Shunan $\mathrm{Gu}^{3}$, Guangrong $\mathrm{Yu}^{4}$, Feng Yin ${ }^{1}$ \\ ${ }^{1}$ Department of Joint Surgery, Shanghai East Hospital, Tongji University, School of Medicine, Shanghai 200120, China; ${ }^{2}$ Orthopaedic Hospital \\ Research Center, David Geffen School of Medicine, University of California, Los Angeles, Los Angeles, CA, USA; ${ }^{3}$ Southern Medical University, \\ Guangzhou 510000, China; ${ }^{4}$ Department of Orthopedics, Tongji Hospital, Tongji University, School of Medicine, Shanghai 200120, China \\ Contributions: (I) Conception and design: G Wu, F Yin; (II) Administrative support: F Yin; (III) Provision of study materials or patients: G Wu, S Gu, \\ G Yu; (IV) Collection and assembly of data: G Wu; (V) Data analysis and interpretation: G Wu; (VI) Manuscript writing: All authors; (VII) Final \\ approval of manuscript: All authors. \\ Correspondence to: Feng Yin. Department of Joint Surgery, Shanghai East Hospital, Tongji University, School of Medicine, Shanghai 200120, China. \\ Email: 001yinfeng@sina.com.
}

\begin{abstract}
Background: This study aimed to compare the biomechanical outcomes of the isolated $4^{\text {th }}$ or $5^{\text {th }}$ tarsometatarsal (TMT) joint arthrodesis with the whole lateral TMT joints arthrodesis.

Methods: Ten cadaveric lower legs underwent isolated $4^{\text {th }}$ TMT joint arthrodesis, $5^{\text {th }}$ TMT joint arthrodesis, and whole lateral TMT joints arthrodesis in sequence. Texson F-scan and K-scanTM joint sensor were used to test the medial and lateral plantar pressure and the pressure of calcaneocuboid joint.

Results: Compared with the intact foot, the lateral forefoot pressure increased significantly $(\mathrm{P}<0.05)$ after $4^{\text {th }}$ TMT joint fusion. The medial forefoot pressure was significantly lower in the $5^{\text {th }}$ TMT joint fusion than that in the intact foot $(\mathrm{P}<0.05)$ and the $4^{\text {th }}$ TMT joint fusion $(\mathrm{P}<0.05)$, but higher than that in the whole lateral TMT joints fusion $(\mathrm{P}<0.05)$. On the contrary, the lateral forefoot pressure was significantly higher in the $5^{\text {th }}$ TMT joint fusion than that in the intact foot and the $4^{\text {th }}$ TMT joint fusion, but lower than that in the whole lateral TMT joints fusion $(\mathrm{P}<0.05)$. The medial forefoot pressure was the lowest $(\mathrm{P}<0.05)$ and lateral forefoot pressure was the highest $(\mathrm{P}<0.05)$ in the whole lateral TMT joints fusion. The calcaneocuboid joint pressure increased respectively with the intact foot being the lowest, followed by the isolated $4^{\text {th }}$ TMT joint arthrodesis, the isolated $5^{\text {th }}$ TMT joint arthrodesis, and the whole lateral TMT joints arthrodesis $(\mathrm{P}<0.05)$.

Conclusions: The isolated $4^{\text {th }}$ or $5^{\text {th }}$ TMT joint arthrodesis has less impact on the pressure of forefoot and adjacent joints than the whole lateral TMT joints arthrodesis. The isolated $4^{\text {th }}$ TMT joint arthrodesis has the lowest influence on the pressure of forefoot and adjacent joints.
\end{abstract}

Keywords: Tarsometatarsal; arthrodesis; midfoot lateral column

Submitted Jun 12, 2019. Accepted for publication Sep 22, 2019.

doi: $10.21037 /$ atm.2019.10.21

View this article at: http://dx.doi.org/10.21037/atm.2019.10.21

\section{Introduction}

As an important connection between the forefoot and midfoot, tarsometatarsal (TMT) joints have various complicated functions in both standing and walking postures. According to the anatomic characteristics and functions, Myerson (1) divided the midfoot structures into three parts: the medial column, the middle column, and the lateral column (Figure 1). Injuries to the TMT joints account for $0.2 \%$ of all orthopedic injuries with 55,000 cases per year (2). Injuries to the $4^{\text {th }}$ and $5^{\text {th }}$ TMT joints are seen in various traumatic events. Current researches (3-5) focus on the management of the three medial TMT joints, while scarce literature has discussed the lateral TMT joints. 


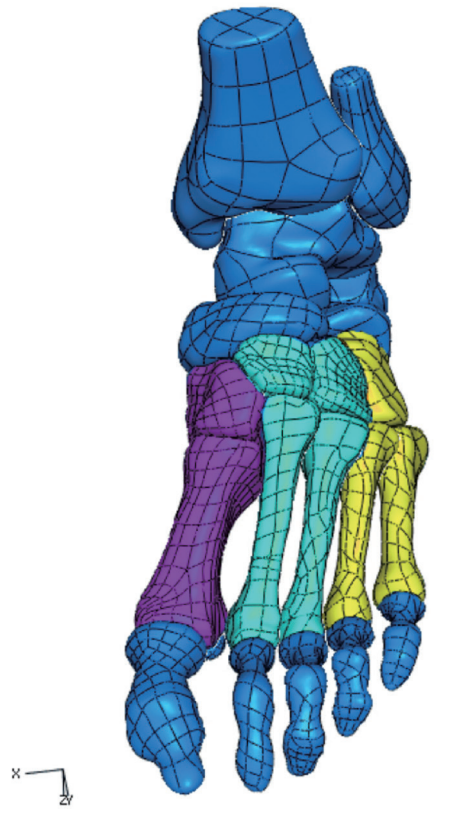

Figure 1 The theory of midfoot three columns from Myerson. Pink: midfoot medial column; Green: midfoot middle column; Yellow: midfoot lateral column.

Anatomically, the $4^{\text {th }}$ and $5^{\text {th }}$ TMT joints consist of the $4^{\text {th }}$ and $5^{\text {th }}$ cuboid-metatarsal (CMT) joints and the $4^{\text {th }}-5^{\text {th }}$ intermetatarsal joint. Unlike the wedge-shaped configuration of the other cuneometatarsal joints, the $4^{\text {th }}$ and $5^{\text {th }} \mathrm{CMT}$ joints without specific convexity or concavity are much flatter (6). Cadaveric studies $(7,8)$ also indicated that the trapeziform or triangle articular contour of the $4^{\text {th }}$ and $5^{\text {th }}$ CMT joints would provide the two lateral joints a large range of motion. Besides, the stability of the $4^{\text {th }}$ and $5^{\text {th }}$ TMT joints is largely maintained by the ligamentous integrity. Such ligamentous integrity consists of the capsule between the cuboid and base of metatarsals, the dorsal and plantar ligaments, the intermetatarsal interosseus ligament, and additional supports from some tendons, like the interosseous muscles and plantar fascia (9-12). However, similar to the unstable joints, limited strength of ligaments also results in the large range of motion of the $4^{\text {th }}$ and $5^{\text {th }}$ TMT joints. Therefore, the $4^{\text {th }}$ and $5^{\text {th }}$ TMT joints, as a relatively independent unit of the lateral column, are designed to have a high mobility accommodating the forefoot on uneven terrain $(7,13)$. This anatomic characteristic is a predisposing factor of the injuries of $4^{\text {th }}$ and $5^{\text {th }}$ TMT joints and results in the difficulty of choosing optimal treatments. Injuries of $4^{\text {th }}$ and $5^{\text {th }}$ TMT joints usually combine with the fractures of other midfoot columns, such as the medial column or the middle column, making it easily misdiagnosed (14).

Injuries of the midfoot are usually caused by a direct or indirect force, which can be divided into four different types according to modified Myerson classification system (15) (Figure 2). The isolated $4^{\text {th }}$ or $5^{\text {th }}$ TMT joint injury especially long-term severe arthritis is rarely reported. Thus, the surgical treatments to such kinds of injuries are still controversial. At present, the surgical managements of the $4^{\text {th }}$ and $5^{\text {th }}$ TMT injuries can mainly be classified as open reduction and internal fixation, TMT arthrodesis, and arthroplasty (16-18). This study mainly discussed the $4^{\text {th }}$ and $5^{\text {th }}$ TMT arthrodesis. Most studies suggested motion-preserving procedures since they believed that arthrodesis of lateral column could increase the risk of post-operative nonunion, pain, foot stiffness, adjacent joints degeneration, and stress fractures $(19,20)$. However, the arthrodesis of lateral TMT may be the only choice when structural deformity or severe pain occurred. Raikin et al. (21) reported 23 cases with severe deformity and pain, who undergone the arthrodesis of $4^{\text {th }}$ and $5^{\text {th }}$ TMT joints, and the results showed that the arthrodesis of $4^{\text {th }}$ and $5^{\text {th }}$ TMT joints produced good outcomes such as pain relief and functional improvement, but 13 cases still complained about subjective stiffness of the lateral foot. Although a few studies suggested that the arthrodesis of $4^{\text {th }}$ and $5^{\text {th }}$ TMT joints could obtain pain relief and functional improvement, these studies were all short-term to mid-term researches without a proper evaluation of the influence on the normal midfoot biomechanics.

The purpose of this cadaveric study was to compare the effects of isolated $4^{\text {th }}$ or $5^{\text {th }}$ TMT joint arthrodesis with whole lateral TMT joint arthrodesis on the foot plantar pressure and the pressure of adjacent joint which can indirectly reflect the effects of different types of arthrodesis on midfoot lateral column.

\section{Methods}

The specimens were provided by Tongji University, School of Medicine. Ten fresh frozen cadaveric lower extremities were stored at $-20^{\circ} \mathrm{C}$ and thawed to room temperature before testing. Mean age of the specimens was 46.3 (ranging from 26 to 60) years old. There were six male and four female specimens. There were five left feet and five right feet. This was a cadaveric study, thus the ethics approval was not required for this study. 

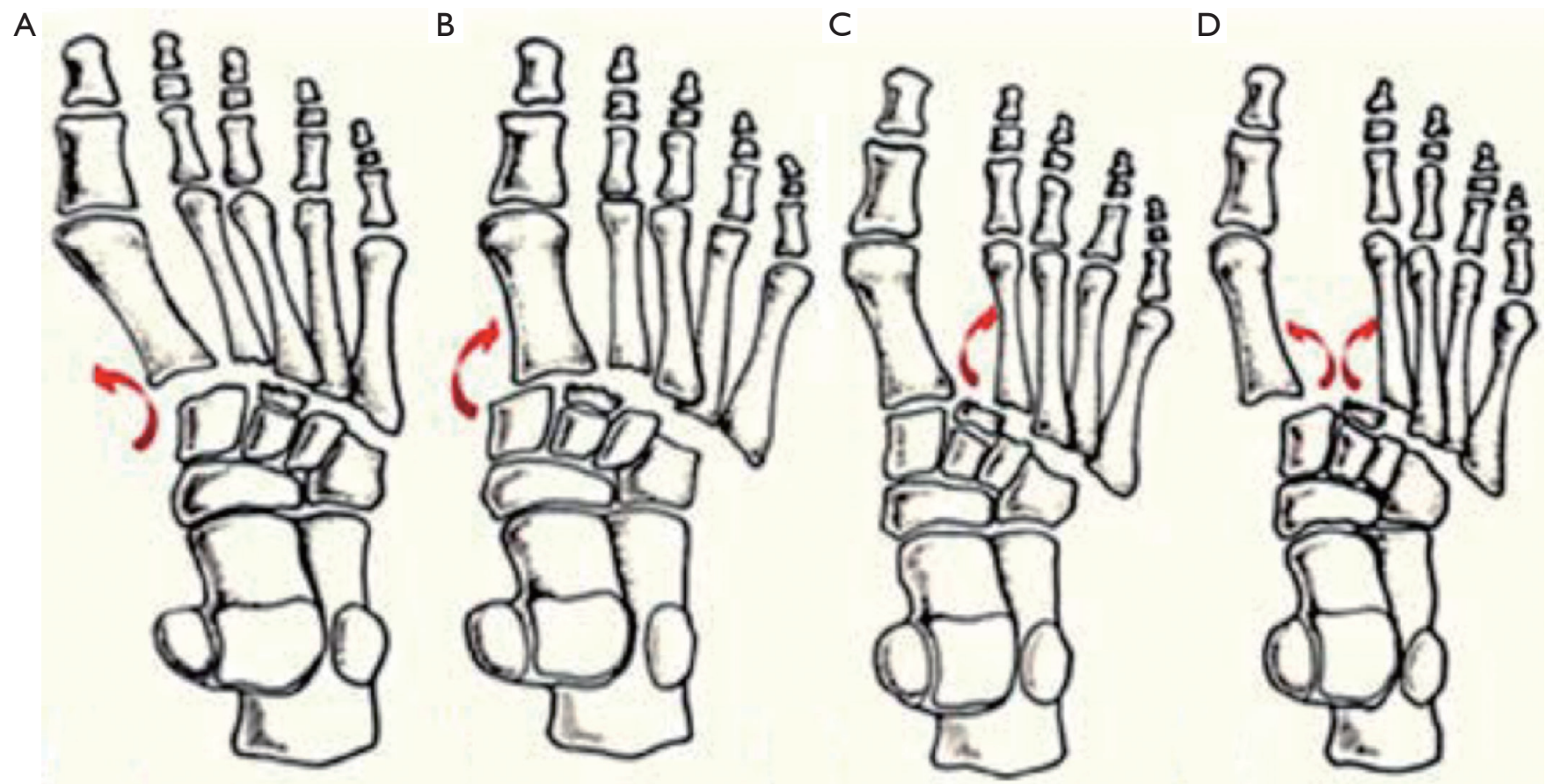

Figure 2 Patterns of injuries to the 4th and fifth TMT joints. (A, B) In Myerson type A, all the TMT joints dislocated medially or laterally. (C) In type B2, one or more of the lateral four TMT joints dislocated laterally. (D) In type C2, the first TMT joint and the lateral four TMT joints dislocated in a divergent way.

The femur was transected approximately $15 \mathrm{~cm}$ above the condyles of femur. The knee joint was fused by using three $3.5-\mathrm{mm}$ Steinmann pins. The skin, subcutaneous tissues, neurovascular bundle, and extensor tendons were removed without any injury of the bony and ligamental structures. The Achilles tendon, peroneus longus, peroneus brevis, flexor digitorum longus, flexor hallucis longus, and posterior tibial tendon were exposed, and left for tensile loading (Figure 3). The fusion fixation was done with the $3.5-\mathrm{mm}$ fully threaded cannulated screws. For the isolated $4^{\text {th }}$ TMT joint fusion, a screw was placed across the $4^{\text {th }}$ metatarsal into the cuboid. For the whole midfoot lateral column fusion, another screw was placed in an axial direction from the $5^{\text {th }}$ metatarsal into the cuboid. And the starting point of this screw was on the lateral apex of the triangle-shaped $5^{\text {th }}$ metatarsal to obtain optimal fixation. For the isolated $5^{\text {th }}$ TMT joint fusion, the screw for isolated $4^{\text {th }}$ TMT joint fusion was removed (Figure 4).

In this study, each specimen was examined in a quasidynamic state simulating two-legged stance with the tibia at $90^{\circ}$ to the floor. The specimens were mounted onto a holding device to maintain consistent vertical alignment during testing. The device was attached to a loading frame
(DDL 20, Changchun Academy of Machinery Science \& Technology Co. Ltd). Each tendon of muscle was stripped then sutured. The tensile load was applied to them: posterior tibial tendon, $40 \mathrm{~N}$; flexor digitorum longus, $22 \mathrm{~N}$; flexor hallucis longus, $22 \mathrm{~N}$; peroneus brevis and peroneus longus combined, $35 \mathrm{~N}$; and Achilles, $200 \mathrm{~N}$. The tensile load was associated with the peak contractile tension of the triceps surae strength percentage, work percentage, and cross-sectional area $(22,23)$. Before each measurement, an external 72 to $400 \mathrm{~N}$ straight axial force was applied cyclically at $0.5 \mathrm{~Hz}$ for 30 cycles to keep muscle tensioning and mechanical equilibrium.

Then the specimens were maintained at an axial load of half the body weight $(350 \mathrm{~N})$. Forefoot medial/lateral and hind-foot plantar pressure measurements were obtained by the F-Scan computerized pressure measurement system (Tekscan, Inc. South Boston, MA, USA) at a rate of $50 \mathrm{~Hz}$. Meanwhile, calcaneocuboid joint pressures were measured by the K-scan ${ }^{\text {TM }}$ (Tekscan, Inc. South Boston, MA, USA) at a rate of $50 \mathrm{~Hz}$. Only one of the four available K-scan sensor pads was used due to the small surface area of the calcaneocuboid joint. The above procedures were replicated for ten times. Sensors were kept in place on each specimen 

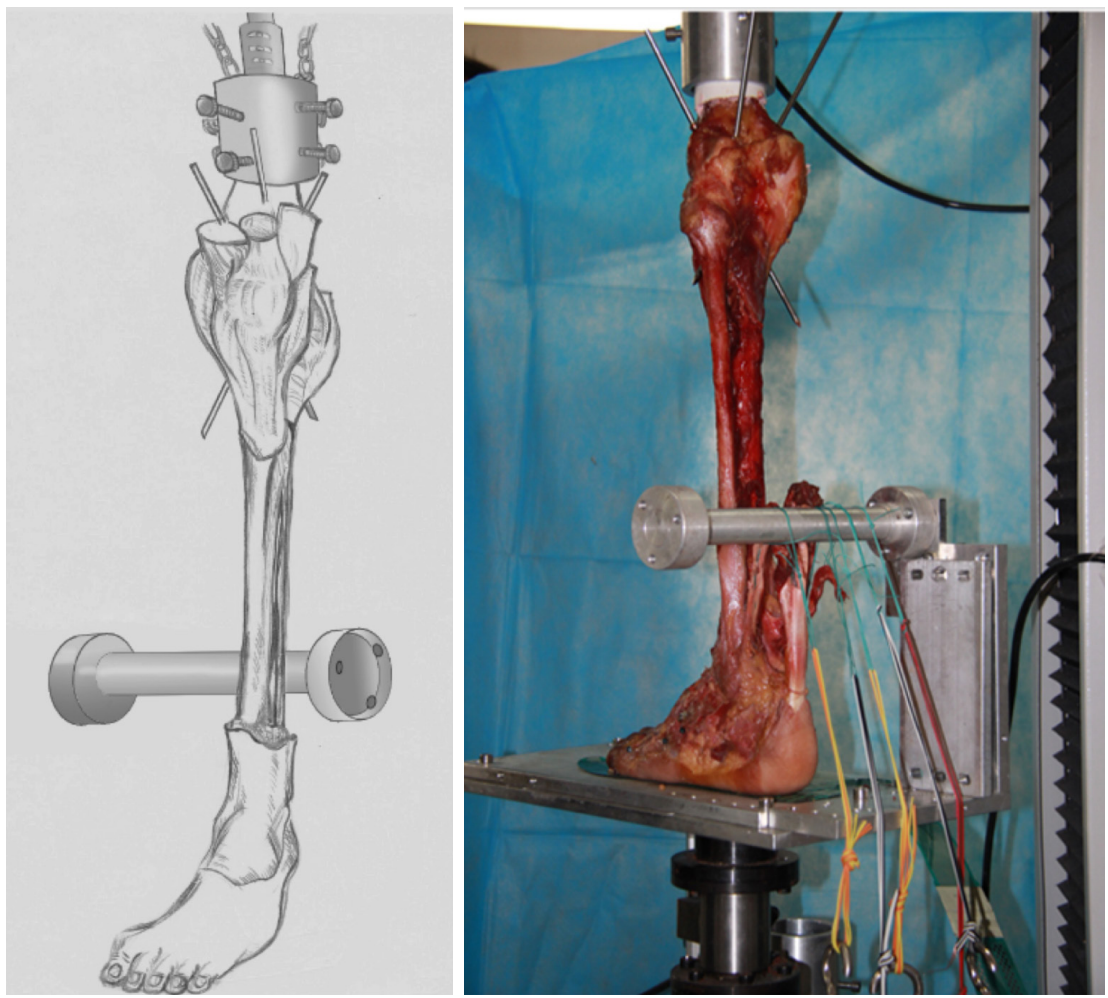

Figure 3 Photograph shows placement of specimen in load frame with tendons sutured for loading with simulated muscle forces.
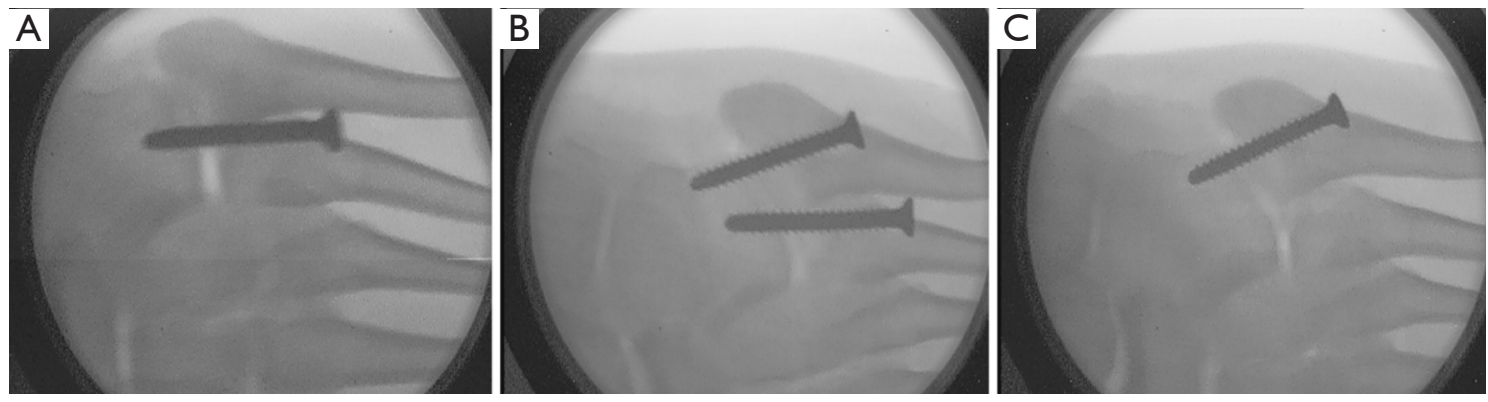

Figure 4 Radiographs show AP view of isolated $4^{\text {th }}$ and $5^{\text {th }}$ TMT joint arthrodesis and whole midfoot lateral column arthrodesis.

throughout testing. The peak pressures were averaged by the software.

The calibration was confirmed that the load measured by the pressure sensors during testing was within $8 \%$ of the applied load (24). The calibration method has been reported previously with the Tekscan software in a study of patellofemoral contact pressure across the trochlear surface (25). With each specimen, measurements were conducted under four conditions: the intact foot, the isolated $4^{\text {th }}$ TMT joint fusion, the $4^{\text {th }}$ and $5^{\text {th }}$ TMT joints fusion, and the isolated $5^{\text {th }}$ TMT joint fusion. Both plantar pressures and calcaneocuboid joint pressures were recorded under each condition.

\section{Statistical analysis}

All the radiographic parameters and plantar pressures were assessed under each condition to identify any difference. All data were expressed as mean \pm standard deviation, and analysis was conducted with SPSS 20.0 by using one-way ANOVA analysis of variance. LSD was used in pairwise comparison. Significance was set at $\mathrm{P}<0.05$. 
Table 1 Forefoot pressure of patients

\begin{tabular}{|c|c|c|c|c|c|c|c|c|}
\hline $\begin{array}{l}\text { Forefoot } \\
\text { pressure }\end{array}$ & \multicolumn{2}{|c|}{ Intact } & \multicolumn{2}{|c|}{ 4th TMT joint fusion } & \multicolumn{2}{|c|}{ 5th TMT joint fusion } & \multicolumn{2}{|c|}{ Whole lateral column fusion } \\
\hline Average $(\mathrm{kPa})$ & $30.7 \pm 2.1$ & $23.8 \pm 1.6$ & $30.4 \pm 2.0$ & $24.8 \pm 1.7$ & $29.4 \pm 2.0$ & $25.8 \pm 1.9$ & $26.6 \pm 2.2$ & $29.0 \pm 1.6$ \\
\hline
\end{tabular}

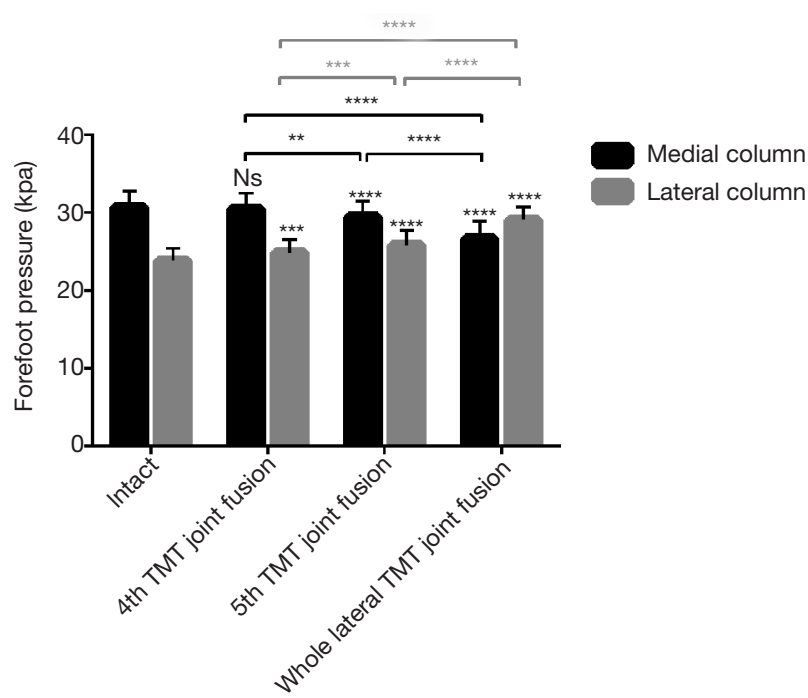

Figure 5 Forefoot pressure after different joint version. The lateral forefoot plantar pressure was the highest and the medial forefoot pressure was the lowest in whole lateral TMT joints fusion. ${ }^{* *} \mathrm{P}<0.01,{ }^{* * *} \mathrm{P}<0.001,{ }^{* * * *} \mathrm{P}<0.0001$.

\section{Results}

In this study, the forefoot had been divided into medial and lateral column by the axis of the $3^{\text {rd }}$ metatarsal. The lateral forefoot plantar pressure $(32.9 \pm 2.3 \mathrm{kPa})$ was the highest $(\mathrm{P}<0.05)$ and the medial forefoot pressure $(22.6 \pm 2.2 \mathrm{kPa})$ was the lowest $(\mathrm{P}<0.05)$ in whole lateral TMT joints fusion. The influence on the forefoot pressure of the $5^{\text {th }}$ TMT fusion was weaker than the whole lateral TMT joints fusion. The lateral forefoot pressure $(28.2 \pm 2.6 \mathrm{kPa})$ in the $5^{\text {th }} \mathrm{TMT}$ joint fusion was lower $(\mathrm{P}<0.05)$ than that in the whole lateral TMT joints fusion but higher $(\mathrm{P}<0.05)$ than any other conditions. The medial forefoot pressure $(25.9 \pm 2.4 \mathrm{kPa})$ in the $5^{\text {th }} \mathrm{TMT}$ joint fusion was higher than that in the whole lateral TMT joints fusion but lower than that in the intact foot and the $4^{\text {th }}$ TMT joint fusion $(\mathrm{P}<0.05)$. The $4^{\text {th }}$ TMT joint fusion resulted in the minimal impact on the forefoot pressure. The difference of medial forefoot pressure between the $4^{\text {th }}$ TMT joint fusion $(29.9 \pm 2.6 \mathrm{kPa})$ and the intact foot $(31.4 \pm 2.7 \mathrm{kPa})$ was not significant $(\mathrm{P}>0.05)$. The lateral forefoot pressure in the $4^{\text {th }}$ TMT joint fusion $(24.4 \pm 2.9 \mathrm{kPa})$ was higher $(\mathrm{P}<0.05)$ than that in the intact foot $(20.6 \pm 2.4 \mathrm{kPa})$ but lower $(\mathrm{P}<0.05)$ than that in the $5^{\text {th }}$ TMT joint fusion and whole lateral TMT joints fusion (Table 1 and Figure 5).

The calcaneocuboid joint pressures from low to high respectively $(\mathrm{P}<0.05)$ are in the intact foot $(1,061.3 \pm 112.9 \mathrm{kPa})$, the isolated $4^{\text {th }}$ TMT joint arthrodesis $(1,251.3 \pm 155.0 \mathrm{kPa})$, the isolated $5^{\text {th }}$ TMT joint arthrodesis $(1,500.1 \pm 121.6 \mathrm{kPa})$, and the whole lateral TMT joints arthrodesis $(1,686.3 \pm 156.2 \mathrm{kPa}$ ) (Table 2 and Figures 6,7).

\section{Discussion}

In this study, these results indicated that any fusion regarding midfoot lateral column could alter foot biomechanics. Such outcomes were consistent with previous anatomical and biomechanical studies about midfoot lateral column $(1,17,26,27)$. Arthrodesis as the one of the last options for the late-stage arthropathy of midfoot lateral column is still controversial.

Previous studies $(7,8,13)$ have shown that the $4^{\text {th }}$ and $5^{\text {th }}$ TMT joints were allowed for larger mobility than other TMT joints which could accommodate the forefoot on uneven terrain and buffer the pressure during walking. Consequently, arthrodesis regarding midfoot lateral column was not recommended usually. Komenda et al. (28) conducted a retrospective study in 32 patients with TMT joints fusion and reported that two patients with fusion of all the $5^{\text {th }}$ TMT joints required subsequent osteotomies due to intractable metatarsalgia. A study by Yu GR et al. (29) also indicated that rigid fixation of the $4^{\text {th }}$ and $5^{\text {th }}$ TMT joints required a large dissection of soft tissues which was not biomechanically desirable. Sangeorzan et al. (30) followed up 16 patients after TMT joints fusion and reported that five patients had poor outcomes. Unfortunately, these reports enrolled a small number of cases, without addressing the specific problem itself. Under many situations, it was hard to achieve correction of the residual deformity without providing rigid lateral supports by reduction and arthrodesis. 
Table 2 Calcaneocuboid joint pressures of patients

\begin{tabular}{lcccc}
\hline $\begin{array}{l}\text { Calcaneocuboid joint } \\
\text { pressures }\end{array}$ & Intact & $4^{\text {th }}$ TMT joint fusion & $5^{\text {th }}$ TMT joint fusion & Whole lateral column fusion \\
\hline Average $(\mathrm{kPa})$ & $1,073.4 \pm 118.5$ & $1,143.5 \pm 176.8$ & $1,504.4 \pm 148.4$ & $1,582.7 \pm 184.7$ \\
\hline
\end{tabular}

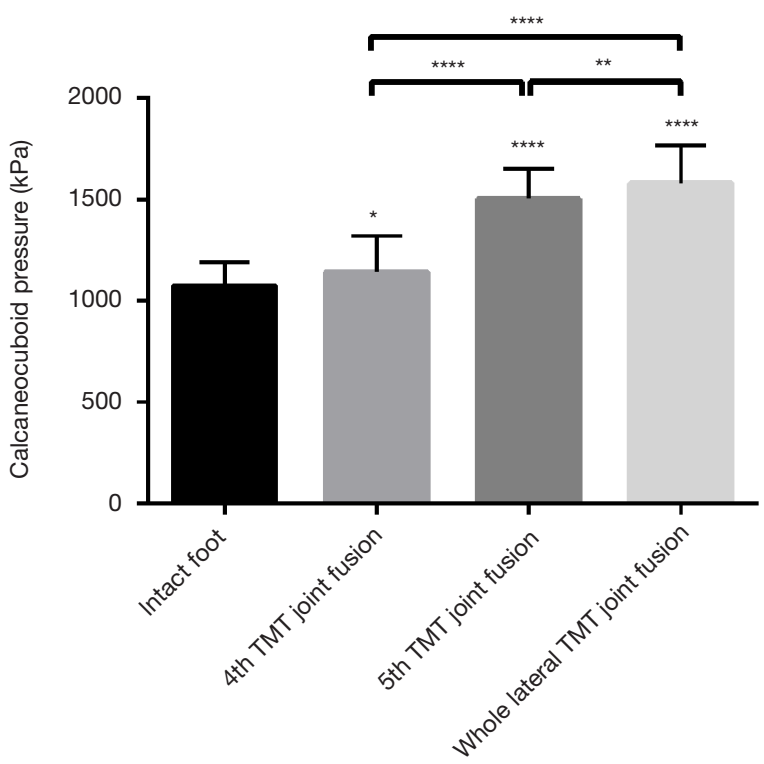

Figure 6 Calcaneocuboid joint pressures after different joint version. The calcaneocuboid joint pressures from low to high respectively are intact foot, isolated 4th TMT joint arthrodesis, isolated 5th TMT joint arthrodesis and whole lateral TMT joints arthrodesis. ${ }^{*} \mathrm{P}<0.05,{ }^{* *} \mathrm{P}<0.01,{ }^{* * *} \mathrm{P}<0.001,{ }^{* * *} \mathrm{P}<0.0001$.

Moreover, there were studies showing optimistic results. Raikin et al. (21) indicated that arthrodesis of the $4^{\text {th }}$ and $5^{\text {th }}$ TMT joints could and should be done in patients with uncorrectable lateral midfoot collapse and rocker bottom foot deformity. Twenty patients showed good outcomes after arthrodesis of the $4^{\text {th }}$ and $5^{\text {th }}$ TMT joints. Rammelt et al. (31) followed up 22 patients with fractures and dislocations of the TMT (Lisfranc) joints and concluded that the difference between patients with medial column fusion and those with the whole tarsometatarsal joint fusion was not significant.

Nevertheless, there is still no experiment regarding isolated lateral column fusion. In this study, a hypothesis was brought up that if the isolated $4^{\text {th }}$ or $5^{\text {th }}$ TMT joint reduction and fusion could provide enough lateral support, it would be possible to reduce the influence on anatomic structures of midfoot. In this study, the medial and lateral plantar foot pressure and the adjacent joint pressure changes after three types of midfoot lateral column (isolated $4^{\text {th }}$ or $5^{\text {th }}$ TMT joint and whole lateral column) fusion were analyzed. These results were surprising that both isolated $4^{\text {th }}$ and $5^{\text {th }}$ TMT joint arthrodesis exerted less influence on normal anatomic structures of foot when compared with the whole midfoot lateral column fusion which could alter foot biomechanics to a significant degree, while the $4^{\text {th }}$ TMT joint arthrodesis showed the minimal impact. The outcomes supported our hypothesis that the isolated $4^{\text {th }}$ or $5^{\text {th }}$ TMT joint could reduce the effects on the physical structures of midfoot. According to previous studies $(10,11,27)$, the main reason may be that the capsules of the $4^{\text {th }}$ and $5^{\text {th }}$ TMT joints are independent. The stability of the $4^{\text {th }}$ and $5^{\text {th }}$ TMT joints largely depends on the ligamentous integrity. Either isolated $4^{\text {th }}$ or $5^{\text {th }}$ TMT joint was fused, the other joint could still maintain the lateral column function to some extent. Thus, the effects of isolated $4^{\text {th }}$ or $5^{\text {th }}$ TMT joint arthrodesis on forefoot plantar pressure and calcaneocuboid joint were much less than the whole lateral column arthrodesis.

There were still some limitations of this study. It was a cadaveric study which did not simulate the clinical settings exactly. The specimens were cyclically loaded in a neutral position which could not imitate the real gait phase in uneven terrain. Moreover, the specimens did not have pathologic changes which might typically found in real patients. In order to achieve the maximum control of variable, the specimens were not removed during the experiment and the joints were fused without resecting the joint surfaces. Thus, further biomechanical studies should be conducted to investigate the influences of different models on uneven surface.

Taken together, the isolated $4^{\text {th }}$ or $5^{\text {th }}$ TMT joint arthrodesis has less influence on the midfoot lateral column compared with the whole lateral column arthrodesis. In order to reduce the influence on the normal midfoot biomechanics, the whole midfoot lateral column arthrodesis should be avoided if the isolated $4^{\text {th }}$ or $5^{\text {th }}$ TMT joint arthrodesis can provide enough midfoot lateral support. In patients with uncorrectable lateral midfoot collapse or rocker bottom foot deformity, fusion of the whole lateral 
A

B

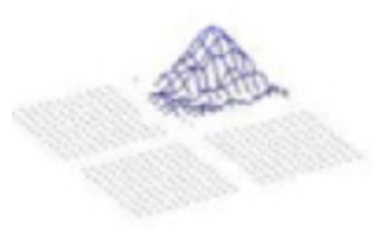

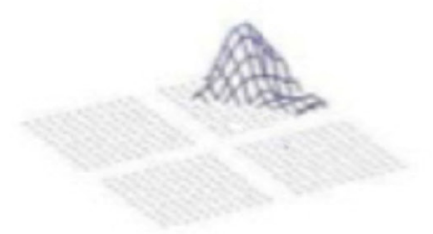
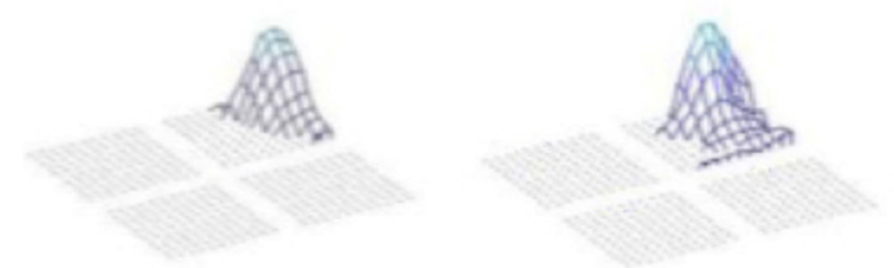

Figure 7 The photographs of joint pressure distribution by K-scan ${ }^{\mathrm{TM}}$ joint sensor. (A) Calcaneocuboid joint's pressure of intact foot; (B) calcaneocuboid joint's pressure of $4^{\text {th }}$ TMT joint arthrodesis; (C) calcaneocuboid joint's pressure of $5^{\text {th }}$ TMT joint arthrodesis; (D) calcaneocuboid joint's pressure of Whole midfoot lateral column arthrodesis.

column may be unavoidable. In such cases, the isolated $4^{\text {th }}$ or $5^{\text {th }}$ TMT joint arthrodesis combined with arthroplasty of the other joint can be a better option.

\section{Acknowledgments}

Funding: This study was funded by Key Specialty Construction Project of Pudong Health and Family Planning Commission of Shanghai (Grant No. PWZzk2017-25).

\section{Footnote}

Conflicts of Interest: The other authors have no conflicts of interest to declare.

Etbical Statement: The authors are accountable for all aspects of the work in ensuring that questions related to the accuracy or integrity of any part of the work are appropriately investigated and resolved. This was a cadaveric study, thus the ethics approval was not required for this study.

\section{References}

1. Myerson MS, Fisher RT, Burgess AR, et al. Fracture dislocations of the tarsometatarsal joints: end results correlated with pathology and treatment. Foot Ankle 1986;6:225-42.

2. Uppal HS. Open Reduction Internal Fixation of the Lisfranc Complex. J Orthop Trauma 2018;32 Suppl 1:S42-3.

3. Dalal D, Curry C, Carter R, et al. Surgical Treatment of Lisfranc Injury With Plantar Plate Approach. J Foot Ankle Surg 2018;57:794-800.
4. Ho NC, Sangiorgio SN, Cassinelli S, et al. Biomechanical comparison of fixation stability using a Lisfranc plate versus transarticular screws. Foot Ankle Surg 2019;25:71-8.

5. Yu X, Li WL, Pang QJ, et al. Finite element analysis of locking plate and $1 / 4$ tubular plate for first tarsometatarsal joint fracture-dislocation. J Int Med Res 2017;45:1528-34.

6. Peicha G, Labovitz J, Seibert FJ, et al. The anatomy of the joint as a risk factor for Lisfranc dislocation and fracturedislocation. An anatomical and radiological case control study. J Bone Joint Surg Br 2002;84:981-5.

7. Hatem SF. Imaging of lisfranc injury and midfoot sprain. Radiol Clin North Am 2008;46:1045-60, vi.

8. Qiao YS, Li JK, Shen H, et al. Comparison of Arthrodesis and Non-fusion to Treat Lisfranc Injuries. Orthop Surg 2017;9:62-8.

9. Clare MP. Lisfranc injuries. Curr Rev Musculoskelet Med 2017;10:81-5.

10. Panchbhavi VK, Molina Dt, Villarreal J, et al. Threedimensional, digital, and gross anatomy of the Lisfranc ligament. Foot Ankle Int 2013;34:876-80.

11. Castro M, Melao L, Canella C, et al. Lisfranc joint ligamentous complex: MRI with anatomic correlation in cadavers. AJR Am J Roentgenol 2010;195:W447-55.

12. Milankov M, Miljkovic N, Popovic N. Concomitant plantar tarsometatarsal (Lisfranc) and metatarsophalangeal joint dislocations. Arch Orthop Trauma Surg 2003;123:95-7.

13. Aronow MS. Treatment of the missed Lisfranc injury. Foot Ankle Clin 2006;11:127-42, ix.

14. Saab M. Lisfranc fracture--dislocation: an easily overlooked injury in the emergency department. Eur J Emerg Med 2005;12:143-6.

15. Jung HG, Myerson MS, Schon LC. Spectrum of 


\section{Page 8 of 8}

operative treatments and clinical outcomes for atraumatic osteoarthritis of the tarsometatarsal joints. Foot Ankle Int 2007;28:482-9.

16. Berlet GC, Hodges Davis W, Anderson RB. Tendon arthroplasty for basal fourth and fifth metatarsal arthritis. Foot Ankle Int 2002;23:440-6.

17. Chang TJ, Soomekh DJ. Lateral column fusions. Clin Podiatr Med Surg 2004;21:129-39.

18. Dudko S KD, Pierzchaa A. Lisfranc injury - fixation with Kirschner wires. Foot Ankle Surg 2004;10:5-8.

19. Shawen SB, Anderson RB, Cohen BE, et al. Spherical ceramic interpositional arthroplasty for basal fourth and fifth metatarsal arthritis. Foot Ankle Int 2007;28:896-901.

20. Schepers T, Kieboom BC, van Diggele P, et al. Pedobarographic analysis and quality of life after Lisfranc fracture dislocation. Foot Ankle Int 2010;31:857-64.

21. Raikin SM, Schon LC. Arthrodesis of the fourth and fifth tarsometatarsal joints of the midfoot. Foot Ankle Int 2003;24:584-90.

22. Xia J, Zhang P, Yang YF, et al. Biomechanical analysis of the calcaneocuboid joint pressure after sequential lengthening of the lateral column. Foot Ankle Int 2013;34:261-6.

23. Tien TR, Parks BG, Guyton GP. Plantar pressures in the forefoot after lateral column lengthening: a cadaver study comparing the Evans osteotomy and calcaneocuboid fusion. Foot Ankle Int 2005;26:520-5.

Cite this article as: $\mathrm{Wu} \mathrm{G}, \mathrm{Gu}$ S, Yu G, Yin F. Effect of different fusion types on kinematics of midfoot lateral column: a comparative biomechanical study. Ann Transl Med 2019;7(22):665. doi: 10.21037/atm.2019.10.21

\section{Wu et al. Fusion types affect midfoot lateral column kinematics}

24. Jung HG, Nicholson JJ, Parks B, et al. Radiographic and biomechanical support for fibular plating of the agility total ankle. Clin Orthop Relat Res 2004:118-24.

25. Beck PR, Thomas AL, Farr J, et al. Trochlear contact pressures after anteromedialization of the tibial tubercle. Am J Sports Med 2005;33:1710-5.

26. Nadaud JP, Parks BG, Schon LC. Plantar and calcaneocuboid joint pressure after isolated medial column fusion versus medial and lateral column fusion: a biomechanical study. Foot Ankle Int 2011;32:1069-74.

27. Yu X, Pang QJ, Yu GR. The injuries to the fourth and fifth tarsometatarsal joints: A review of the surgical management by internal fixation, arthrodesis and arthroplasty. Pak J Med Sci 2013;29:687-92.

28. Komenda GA, Myerson MS, Biddinger KR. Results of arthrodesis of the tarsometatarsal joints after traumatic injury. J Bone Joint Surg Am 1996;78:1665-76.

29. Yu GR YT, Yang YF, Li B, et al. Surgical treatment of the cuboid fractures. Chin J Traum 2010;26:1064-7.

30. Sangeorzan BJ, Veith RG, Hansen ST Jr. Salvage of Lisfranc's tarsometatarsal joint by arthrodesis. Foot Ankle 1990;10:193-200.

31. Rammelt S, Schneiders W, Schikore H, et al. Primary open reduction and fixation compared with delayed corrective arthrodesis in the treatment of tarsometatarsal (Lisfranc) fracture dislocation. J Bone Joint Surg Br 2008;90:1499-506. 